Proc. Indian Acad. Sci. (Earth Planet. Sci.), Vol. 101, No. 4, December 1992, pp. 361-368.

(C) Printed in India.

\title{
On the validity of time-predictable model for earthquake generation in north-east India
}

\author{
V P SINGH, D SHANKER and J SINGH \\ Department of Geophysics, Banaras Hindu University, Varanasi 221005 , India \\ MS received 3 January 1992; revised 27 July 1992
}

\begin{abstract}
North-east India is seismically very active and has experienced many widelydistributed shallow, large earthquakes. Earthquake generation model for the region was studied using seismicity data [(1906-1984) prepared by National Geophysical Data Centre (NGDC), Boulder Colorado, USA]. For establishing statistical relations surface wave magnitudes $\left(M_{s} \geqslant 5 \cdot 5\right)$ have been considered. In the region four seismogenic sources have been identified which show the occurrences of atleast three earthquakes of magnitude $5 \cdot 5 \leqslant M_{s} \leqslant$ 7.5 giving two repeat times. It is observed that the time interval between the two consecutive main shock depends on the preceding main shock magnitude $\left(M_{p}\right)$ and not on the following main shock magnitude $\left(M_{f}\right)$ revealing the validity of time predictable model for the region. Linear relation between logarithm of repeat time $(T)$ and preceding main shock magnitude $\left(M_{p}\right)$ is established in the form of $\log T=c M_{p}+a$. The values of $c$ and $a$ are estimated to be 0.36 and 1.23 , respectively. The relation may be used for seismic hazard evaluation in the region.
\end{abstract}

Keywords. Seismogenic sources; earthquake generation; repeat time.

\section{Introduction}

The study of earthquake generation models has attracted the attention of many scientists in recent years. Many workers (Cornell 1968; Gardner and Knopoff 1974; Papadopoulos and Voidomatis 1987) reported that the occurrence of earthquakes follows a Poisson distribution suggesting memoryless property of seismic-zones. However, Wallace (1970) and Nishenko and Singh (1987) among others reported time-dependent property of earthquake-generating sources for several regions. The proposed time-dependent recurrence models were: slip-predictable model (Bufe et al 1977; McNally and Minster 1981; Singh et al 1981; Wang et al 1982; Kiremidjian and Anagnos 1984) and time-predictable model (Shimazaki and Nakata 1980; Anagnos and Kiremidjian 1984; Papazachos 1989). These models were based on the assumption of constant tectonic stress accumulation rate and association of stress relief with the sequence of earthquakes. The slip-predictable model demands a change in the initial stress keeping the final stress constant whereas the time-predictable model requires fluctuations in final stresses without changing the initial stress level.

Earthquake generation model studies require the assessment of the size (i.e. seismic moment, moment magnitude, stress drop, coseismic slip etc.) of earthquakes. The seismic moment $M_{o}$ and moment magnitude $M$ can be derived from surface wave magnitude, a prerequisite for time-predictable model, using the relation proposed by Purcaru and Berckhemer (1978) and Hanks and Kanamori (1979).

The considered zone includes the Himalayan thrust, Burmese arc and a small 
portion of the Tibetan plateau. The nature of tectonic deformation has been studied by several workers for the Himalayas (Fitch 1970; Verma and Kumar 1987), the Tibetan region (Molnar and Tapponnier 1978; Molnar and Chen 1983) and the Burmese region (Verma et al 1980). The above studies reveal the drifting of Indian plate towards north-east, extension of southern Tibetan region towards south-east and the drifting of Burmese region towards west resulting in widespread distribution of large earthquakes. The region does not show a well-defined subduction zone. A few well-known faults are reported to be seismically active but owing to lack of high quality instrumental data it is difficult to study the earthquake generation model. However, the regions show earthquake epicentres $\left(M_{s} \geqslant 5 \cdot 5\right)$ to be very close to each other at some places and as such it is difficult to decide whether the two main shocks originate from the same fault. Such zones are identified as seismogenic sources. The basic objective of the present paper is to study the time-dependent property of earthquake generation sources.

\section{Seismicity data and analysis}

The earthquake catalogue prepared by the National Geophysical Data Centre, Boulder, Colorado, USA was used for the period 1906-1984 with surface wave magnitude $M_{\mathrm{s}} \geqslant 5 \cdot 5$. As the agency uses a large number of observations to derive magnitude and epicentre, these estimates may be considered to be reliable. Body wave magnitudes saturate at seven whereas surface wave magnitude extends up to nine. Therefore, for all statistical analyses normally surface wave magnitude was used. Presently, the moment magnitude was considered as true as it takes into account the moment of the faulted blocks. The numerical values of surface wave and moment magnitudes were close to each other and the former can easily be used to derive the latter for earthquake generation model studies.

The plot of epicentre is shown in figure 1 for clarity, the lower magnitudes $\left(M_{s}<6.0\right)$ have not been plotted. The clustering pattern of epicentres is seen at four places showing high level seismicity. These places were identified as seismogenic sources and demarcated by elliptical boundaries. For these zones earthquakes of $5.5 \leqslant M_{s} \leqslant 7.5$ were considered for statistical derivation.

In various seismogenic sources the foreshocks and aftershocks were identified from the earthquake distribution in time domain. The earthquakes within 4 years of occurrence of the main shock were considered as foreshocks or aftershocks. For the regions Tengchung, Shingowiyang and Namco a few earthquakes occurred within a year from the occurrence of the main events. But the region Myitkyina showed nine earthquakes distributed over 4 years and 3 months. Of the nine earthquakes four events with the largest magnitude of 6.5 occurred within a year whereas the remaining two occurred within 4 months with the maximum magnitude of 6.5 . The magnitude level of the earthquakes in the above periods was the same. Therefore, their occurrences are considered to be related to each other. The largest earthquake magnitude of 1929 was taken as main shock and the rest as aftershocks. Papazachos (1989) considered the foreshocks and aftershocks which occurred within 4 years of the main shocks.

Table 1 gives the name of the sources and the relevant information. $M$ is defined as the magnitude corresponding to the moment released by the mainshocks, foreshocks and aftershocks of each sequence. Seismic moment is estimated by moment- 


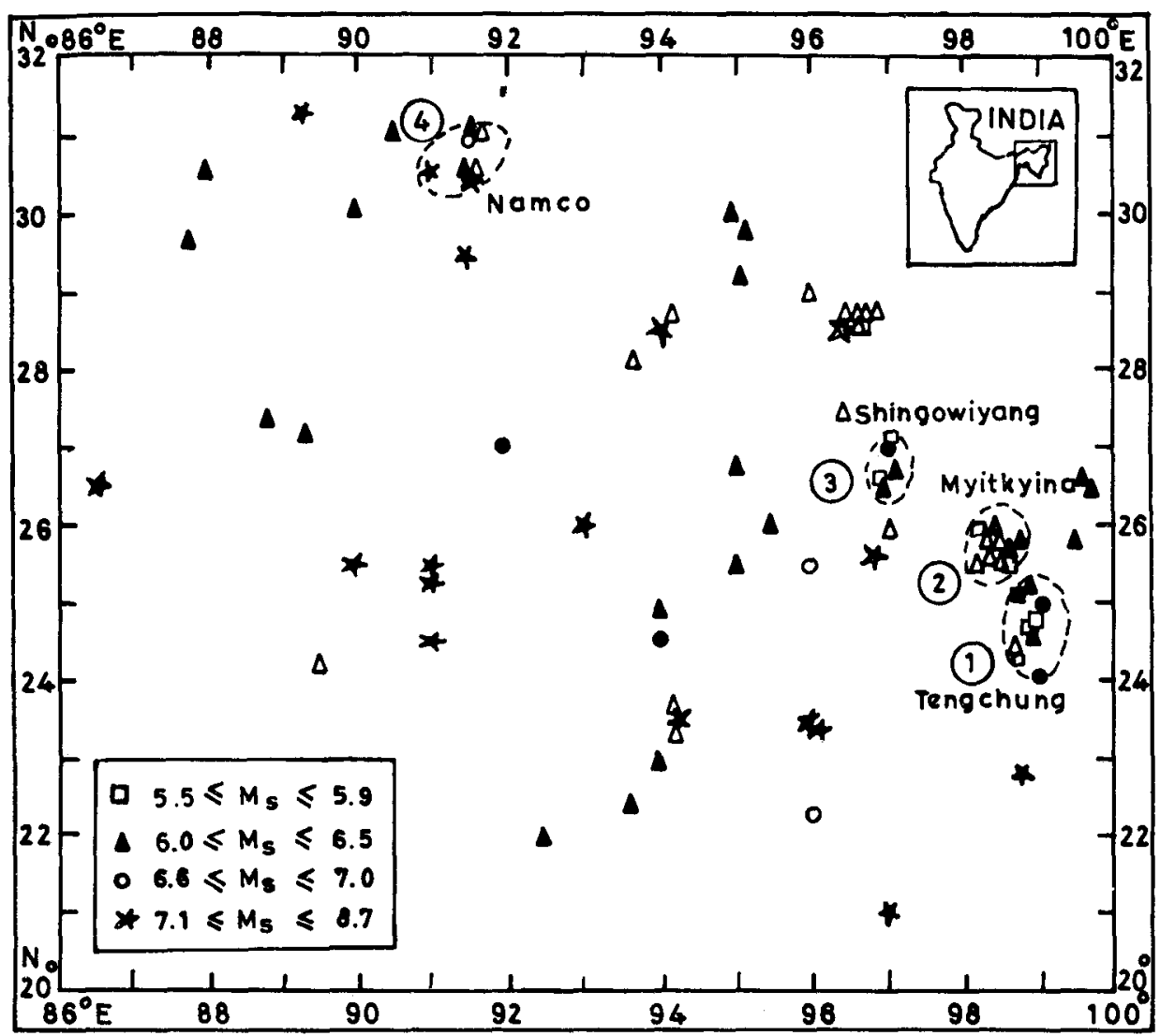

Figure 1. Earthquake epicentre with $M_{s} \geqslant 5.5$ for the period 1906-1984. The four seismogenic sources are demarcated by elliptical boundaries. Open triangle and circle denote foreshock/aftershocks with the magnitude $5 \cdot 5-6 \cdot 4,6 \cdot 5-7 \cdot 4$, respectively.

surface wave magnitude relationship (Purcaru and Berckhemer 1978).

$$
\log M_{o}=1 \cdot 5 M_{s}+16 \cdot 1 \text {. }
$$

Equation (1) is valid only for the range $5 \cdot 0 \leqslant M_{s} \leqslant 7 \cdot 5$. All the considered earthquakes were within this magnitude range except one earthquake of southern Tibetan source i.e. zone 4. This source showed a large earthquake of $M=7.9$ for which the seismic moment was taken as $M_{o}=4.6 \times 10^{27} \mathrm{dyn}-\mathrm{cm}$ (Chen and Molnar 1977). The moment magnitude for the considered events were derived by the relation (Hanks and Kanamori 1979).

$$
M=\frac{2}{3} \log M_{o}-10 \cdot 7 .
$$

It is obvious from table 1 that the differences between the cumulative moment magnitude $(M)$ and the surface wave magnitude are $\leqslant 0.3$ and hence the derived magnitude may be considered as a representative of the size of the events. The minimum magnitude was considered in each case to define the corresponding $M_{p}$ and the repeat time in years. The repeat time $T$ denotes the time from the beginning of one seismic sequence to the initiation of the next sequence. 
Table 1. Information on the earthquakes of four seismogenic sources of north-east India.

\begin{tabular}{|c|c|c|c|c|c|c|c|c|c|c|}
\hline \multirow[b]{2}{*}{ Source } & \multicolumn{2}{|c|}{ Epicentre } & \multicolumn{3}{|c|}{ Date } & \multirow[b]{2}{*}{$M_{s}$} & \multirow[b]{2}{*}{$M$} & \multirow[b]{2}{*}{$M_{\min }$} & \multirow[b]{2}{*}{$M_{p}$} & \multirow[b]{2}{*}{$T_{y}$} \\
\hline & $\mathrm{N}^{\circ}$ & $\mathbf{E}^{\circ}$ & $\mathrm{Y}$ & $\mathbf{M}$ & D & & & & & \\
\hline \multirow[t]{9}{*}{ Tengchung } & $25 \cdot 0$ & $99 \cdot 0$ & 1914 & 03 & 28 & 6.9 & 6.9 & $5 \cdot 6$ & 6.9 & 16 \\
\hline & $25 \cdot 3$ & 98.9 & 1930 & 09 & 25 & $6 \cdot 0$ & $6 \cdot 0$ & $5 \cdot 6$ & $6 \cdot 0$ & 11 \\
\hline & $24 \cdot 0$ & $99 \cdot 0$ & 1941 & 05 & 16 & 6.9 & 6.9 & $5 \cdot 6$ & 6.9 & 20 \\
\hline & $25 \cdot 2$ & $98 \cdot 6$ & 1961 & 06 & 11 & $5 \cdot 6$ & $5 \cdot 6$ & $5 \cdot 6$ & $5 \cdot 6$ & 15 \\
\hline & $24 \cdot 6$ & 98.9 & 1976 & 05 & 29 & 6.9 & $7 \cdot 2$ & $6 \cdot 0$ & 6.9 & 16 \\
\hline & 24.5 & $98 \cdot 7$ & 1976 & 05 & 29 & $7 \cdot 0$ & - & $6 \cdot 0$ & $6 \cdot 0$ & 11 \\
\hline & $24 \cdot 3$ & 98.6 & 1976 & 05 & 31 & $6 \cdot 2$ & - & 6.0 & 6.9 & 35 \\
\hline & 24.9 & 98.8 & 1976 & 06 & 02 & 5.9 & - & 6.9 & 6.9 & 27 \\
\hline & $24 \cdot 7$ & 98.7 & 1976 & 07 & 21 & $6 \cdot 3$ & - & 6.9 & 6.9 & 35 \\
\hline \multirow[t]{11}{*}{ Myitkyina } & 25.8 & 98.7 & 1929 & 10 & 16 & $6 \cdot 5$ & 6.9 & $6 \cdot 3$ & 6.9 & 12 \\
\hline & $25 \cdot 8$ & 98.7 & 1930 & 04 & 28 & $6 \cdot 3$ & - & $6 \cdot 3$ & $6 \cdot 3$ & 13 \\
\hline & $25 \cdot 8$ & 98.4 & 1930 & 09 & 21 & 6.5 & - & 6.5 & 6.9 & 25 \\
\hline & 25.6 & $98 \cdot 3$ & 1930 & 11 & 04 & 6.0 & - & & & \\
\hline & 25.8 & $98 \cdot 3$ & 1930 & 12 & 02 & 6.0 & - & & & \\
\hline & $26 \cdot 0$ & $98 \cdot 0$ & 1931 & 10 & 18 & $5 \cdot 6$ & - & & & \\
\hline & $25 \cdot 5$ & $98 \cdot 5$ & 1932 & 01 & 03 & $5 \cdot 6$ & - & & & \\
\hline & $25 \cdot 5$ & 98.5 & 1933 & 08 & 11 & 6.5 & - & & & \\
\hline & $25 \cdot 5$ & $98 \cdot 2$ & 1934 & 01 & 19 & 6.0 & - & & & \\
\hline & $25 \cdot 4$ & 98.4 & 1941 & 10 & 31 & $6 \cdot 3$ & $6 \cdot 3$ & & & \\
\hline & $26 \cdot 0$ & $98 \cdot 4$ & 1955 & 03 & 22 & 6.5 & 6.5 & & & \\
\hline \multirow[t]{6}{*}{ Shingowiyang } & $27 \cdot 0$ & 97.0 & 1906 & 08 & 31 & 7.0 & $7 \cdot 0$ & 5.0 & $7 \cdot 0$ & 49 \\
\hline & $27 \cdot 2$ & 97.0 & 1955 & 05 & 04 & 5.8 & $5 \cdot 8$ & 5.8 & $5 \cdot 8$ & 7 \\
\hline & $26 \cdot 5$ & $97 \cdot 0$ & 1962 & 09 & 22 & 6.0 & 6.0 & 5.8 & $6 \cdot 0$ & 13 \\
\hline & $26 \cdot 6$ & 97.0 & 1976 & 05 & 30 & $5 \cdot 6$ & $6 \cdot 2$ & 6.0 & $7 \cdot 0$ & 56 \\
\hline & $27 \cdot 7$ & $97 \cdot 1$ & 1976 & 08 & 12 & $6 \cdot 1$ & - & $6 \cdot 0$ & 60 & 13 \\
\hline & & & & & & & & $6 \cdot 2$ & $7 \cdot 0$ & 69 \\
\hline \multirow[t]{7}{*}{ Namco } & $30 \cdot 5$ & 91.0 & 1921 & 10 & 14 & $6 \cdot 3$ & $6 \cdot 3$ & $6 \cdot 3$ & $6 \cdot 3$ & 19 \\
\hline & $31 \cdot 0$ & 91.5 & 1940 & 09 & 03 & $6 \cdot 3$ & $6 \cdot 4$ & $6 \cdot 3$ & $6 \cdot 4$ & 11 \\
\hline & $30 \cdot 5$ & 91.5 & 1940 & 10 & 04 & $6 \cdot 0$ & - & $6 \cdot 4$ & $6 \cdot 4$ & 11 \\
\hline & $31 \cdot 0$ & 91.6 & 1951 & 11 & 17 & $6 \cdot 3$ & $7 \cdot 9$ & & & \\
\hline & $30-9$ & 91.6 & 1951 & 11 & 18 & 6.8 & - & & & \\
\hline & $30 \cdot 5$ & 91.0 & 1951 & 11 & 18 & 7.9 & - & & & \\
\hline & $30 \cdot 5$ & 91.5 & 1952 & 08 & 17 & $7 \cdot 5$ & & & & \\
\hline
\end{tabular}

\section{Relation between the repeat time and $M_{p}$}

Table 1 reveals that the relation between the repeat time and $M_{p}$ may be represented in the form of

$$
\log T=c M_{p}+a,
$$

where $c$ is the gradient of least square line and $a$ the constant. The two parameters depend on the nature of the seismogenic sources such as stress conditions and seismicity levels. As sufficient instrumental data was not available, the estimation of $c$ may show deviation from the actual value. The parameter a depends on the seismicity of each source and the minimum (cut-off) magnitude of the main shock considered. The choice of minimum (cut-off) magnitude level increases the number of repeat times 
(table 1). The repeat time $T$ shows variation from source to source due to different values of $a$ in tectonic zones. In order to establish the relation for all the four seismogenic sources, the average $T$ should be considered. To achieve this initially a linear relation between long $T$ and $M_{p}$ was derived which gives a representative value of $c$ as 0.36 (with correlation coefficient of 0.66 ). The value of $c$ is affected by $a$ and $M_{\min }$ considered in each case. The average repeat times are deduced by putting value of $c$ in equation (3) and the corresponding values of $a$ were determined for all values of $T$ and $M_{p}$ (table 1). This gives the average value $\bar{a}_{m}$. Following the same procedure the different values of $a_{m n}$ were calculated for the corresponding $M_{\min }$ and repeat time for each source, $a_{m n}$ is the value of seismicity for each minimum cutoff magnitude of different seismogenic sources. $T^{*}$ is the average repeat time of the event for average seismicity level for all the seismogenic sources. The average of all the values of $a_{m n}$ would give $\bar{a}_{m n}$. The differences between $\bar{a}_{m}$ and $\bar{a}_{m n}$ are added to $\log T$ to obtain $\log T^{*}$

$$
\text { i.e } \log T^{*}=\log T+\bar{a}_{m}-\vec{a}_{m n} .
$$

The plot of $\log T^{*}$ and $M_{p}$ is shown in figure 2 for which the regression line is derived as

$$
\log T^{*}=0.36 M_{p}-1.23
$$

Equation (5) represents a straight line showing the correlation coefficient of 0.71 . It reflects that the average repeat time increases with increase of $M_{p}$. The same data set is treated separately for establishing relation between $\log T^{*}$ and the following main shock magnitude. The nature of regression line between $M_{f}$ and $\log T^{*}$ is shown in figure 3.

For this case the derived least square line is

$$
\log T^{*}=-0.03 M_{f}+1.48
$$

The correlation coefficient is very low $(-0 \cdot 22)$ for the above equation. It demonstrates that lesser time is needed for larger forthcoming earthquakes suggesting that slippredictable is not valid for the region.

In deriving equation (5) foreshocks and aftershocks were included in cumulative magnitude estimation. Similar analysis for the same data set was also derived excluding

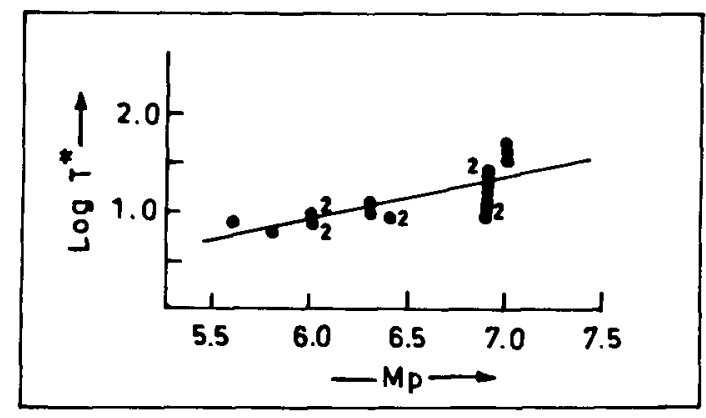

Figure 2. Variation of repeat time $T^{*}$ with the preceding main shock magnitude $M_{p}$. The numeral denotes the number of coinciding points. 


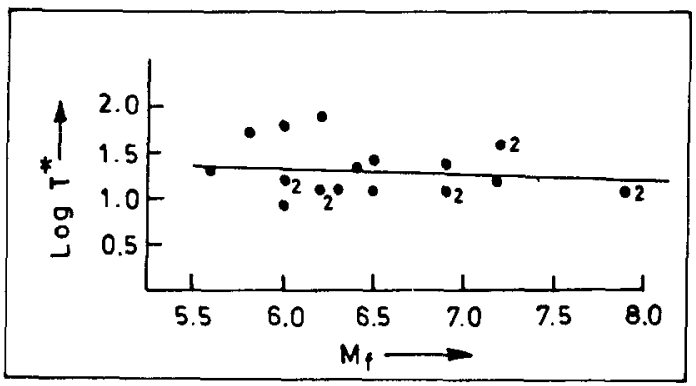

Figure 3. Dependence of repeat time $T^{*}$ with the following main shock magnitude $M_{f}$. The numeral denotes the number of coinciding points.

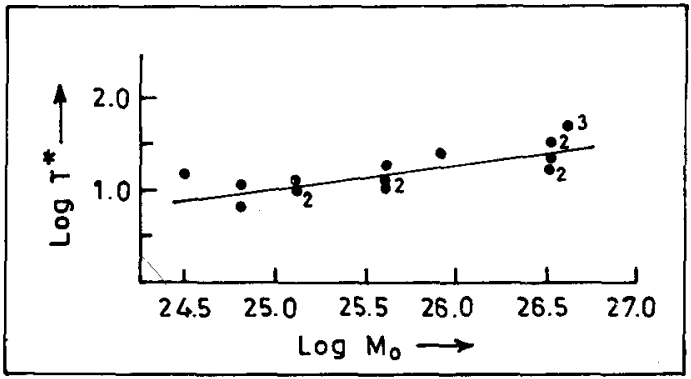

Figure 4. Dependence of repeat time $T^{*}$ on the moment $M_{o}$ of the preceding main event. The numeral denotes the number of coinciding points.

foreshocks and aftershocks as

$$
\log T^{*}=0.41 M_{p}-1.52 \text {. }
$$

Another relation between seismic moment $M_{o}$ and $\log T^{*}$ (figure 4) was also derived showing the linear regression equation

$$
\log T^{*}=0 \cdot 27 \log M_{o}-5 \cdot 70
$$

The correlation coefficients for equations (7) and (8) are 0.68 and 0.76 , respectively. The correlation coefficients suggests that $(5)$ and (8) are statistically significant, while (6) is not. Equations (5), (7) and (8) are almost similar to each other. But (5) is more appropriate because cumulative magnitude is a true representative of the size of the earthquakes. It may be inferred from equations (5), (7) and (8), that time-predictable model is valid for north-east India. Astiz and Kanamori (1984) and Nishenko and Singh (1987) reported the relation between average recurrence time and average seismic moment for Mexico with a slope of 0.333 and 0.299, respectively. Papazachos (1989) reported the slope to be $0 \cdot 28$ for Greece. Shimazaki and Nakata (1980) proposed a similar relation between the repeat times and coseismic slip of the preceding main shock.

\section{Discussion and conclusion}

The time-predictable model has been reported for a number of faults of different regions. Papazachos (1989) reported the validity of time-predictable model for 
seismogenic sources of Greece. The present analysis also supports time predictable model for occurrences of earthquakes in four seismogenic sources of north-east India region which is valid for magnitude $5 \cdot 0 \leqslant M_{s} \leqslant 7.5$ only. The sources show different tectonic environments. A number of faults plane solutions for the sources 1,2 and 3 show strike slip and thrust faultings whereas source 4 is situated in Tibetan region of extensional environments (Molnar and Tapponnier 1978). Equation (5) may be used for long range earthquake prediction in four zones. The reliability of the method depends upon the availability of a good amount of reliable seismicity data. The ambiguity in assessment of forthcoming earthquakes increases for seismogenic sources showing very large repeat times.

From the above analysis it may be concluded that the earthquake generation process in north-east India region supports the time-predictable model i.e. the repeat time of earthquake depends on the preceding main shock magnitude and not on the following main shock. The time of occurrence of forthcoming earthquakes in the seismogenic sources may be estimated by the relation (5) and hence the study may be used for evaluation of seismic hazards in the region.

\section{Acknowledgement}

Financial support provided by the Council of Scientific and Industrial Research, New Delhi is gratefully acknowledged.

\section{References}

Anagnos T and Kiremidjian A S 1984 Stochastic time-predictable model for earthquake occurrences; Bull. Seismol. Soc. Am. 74 2593-2611

Astiz L and Kanamori H 1984 An earthquake doublet in Ometepec, Guerrero, Mexico; Phys. Earth Planet. Int. 34 24-25

Bufe C G, Harsh P W and Burford R O 1977 Steady-state seismic slip-a precise recurrence model; Geophys. Res. Lett. 4 91-94

Chen W P and Molnar P 1977 Seismic moments of major earthquakes and the average rate of slip in Central Asia; J. Geophys. Res. 82 2945-2969

Cornell C A 1968 Engineering seismic risk analysis; Bull. Seismol. Soc. Am. 58 1583-1606

Fitch T J 1970 Earthquake mechanisms of the Himalayan, Burmese and Andaman regions and continental tectonics in Central Asia; J. Geophys. Res. 75 2699-2709

Gardner J K and Knopoff L 1974 Is the sequence of earthquake in southern California with aftershocks removed Poissonian? Bull. Seismol. Soc. Am. 64 1363-1368

Hanks T C and Kanamori H 1979 A moment magnitude scale; J. Geophys. Res. 84 2348-2350

Kiremidjian A S and Anagnos T 1984 Stochastic slip predictable model for earthquake occurrences; Bull. Seismol. Soc. Am. 74 739-755

McNally K C and Minster J B 1981 Nonuniform seismic slip rates along the middle America trench; $J$. Geophys. Res. 86 4949-4959

Molnar P and Tapponnier P 1978 Active tectonics of Tibet; J. Geophys. Res. 83 5361-5375

Molnar P and Chen W P 1983 Focal depth and fault plane solutions of earthquakes under the Tibetan plateau; J. Geophys. Res. 88 1180-1186

Nishenko S P and Singh S K 1987 Conditional probabilities for the recurrence of large and great intraplate earthquakes along the Mexican subduction zone; Bull. Seismol. Soc. Am. 77 2095-2114

Papadopoulos G A and Voidomatis P 1987 Evidence for periodic seismicity in the inner Aegean Seismic Zone; Pure Appl. Geophys. 125 613-628

Papazachos B C. 1989 A time predictable model for earthquake generation in Greece; Bull. Seismol. Soc. Am. $7977-84$

Purcaru G and Berckhemer H 1978 A magnitude scale for very large earthquakes; Tectonophysics 49 189-198 
Shimazaki K and Nakata T 1980 Time-predictable recurrence model for large earthquakes; Geophys. Res. Lett. 7 279-282

Singh S K, Astiz L and Havskov J 1981 Seismic gaps and recurrence periods of large earthquakes along the Mexican subduction zone - a re-examination; Bull. Seismol. Soc. Am. 71 827-843

Verma R K, Mukhopadhyay M and Nag A K 1980 Seismicity and tectonics in south China and Burma; Tectonophysics $6485-96$

Verma R K and Kumar G V.A K 1987 Seismicity and nature of plate movement along the Himalayan arc, North-east India and Arakan-Yoma; Tectonophysics 134 153-175

Wallace R E 1970 Earthquake recurrence intervals on the San Andreas fault; Geol. Soc. Am. Bull. 81 2875-2890

Wang S C, McNally K C and Geller R J 1982 Seismic strain release along the middle America Trench, Mexico; Geophys. Res. Lett. 9 182-185 